\title{
La (no) traducción como estrategia publicitaria: ¿qué se cuela entre las grietas de la lengua con el (ab)uso de la lingua franca?
}

\author{
Alba PÁez Rodríguez \\ Universidad de Salamanca \\ alba.paez.rodriguez@hotmail.com
}

Recibido: 29 de noviembre de 2012

Aceptado: 5 de marzo de 2013

\section{RESUMEN}

En la sociedad capitalista y consumista del s. XXI, la publicidad ha adquirido el don de la ubiquidad y se ha convertido en una herramienta esencial para toda empresa que pretenda sobrevivir en los mercados. En este mundo globalizado, los anuncios han traspasado fronteras, por lo que han necesitado y necesitan de la traducción para surtir los efectos deseados en los distintos países en que se publican. En los últimos años, hemos observado que en el contexto publicitario español se ha introducido una nueva estrategia traductológica que se emplea en un número importante y cada vez mayor de spots televisivos de firmas internacionales y que consiste en su traducción al español mediante subtítulos de manera que el audio permanece en inglés. En este artículo trataremos de demostrar que esta estrategia que nosotros denominamos de "(no) traducción" no es neutra, sino que persigue aprovechar el "capital simbólico" del inglés para seducir al público. La (no) traducción se convierte de este modo en una estrategia publicitaria.

Palabras clave: publicidad, (no) traducción, capital simbólico, connotación, persuasión.

(No) Translation as an Advertising Strategy: What Slips Through the Cracks of the Language with the (Ab)use of the Lingua Franca?

\begin{abstract}
In the $21^{\text {st }}$ century capitalist and consumerist society, advertising can be found everywhere and has become an indispensable tool for every company to succeed in the markets. In this globalized world, advertising has transcended borders and needs translation for achieving its desired effects in every market. Recently, we have noticed in Spain an important change with regard to translation strategies in many television commercials of leading international firms. We have called this increasingly common strategy '(no) translation', since it consists


of subtitling the message while the audio is kept in English. In this article we will try to demonstrate that this (no) translation strategy is not neutral, but rather, it intends to use the 'symbolic capital' of English in order to captivate the audience.

Keywords: advertising, (no) translation, symbolic capital, connotation, persuasion.

Sumario: 1. Introducción. 2. Cuando las campañas internacionales llegan a España. 3. Metodología. 4. Inglés y globalización. 5. El inglés como herramienta de seducción en los spots televisivos emitidos en España. 6. Conclusiones. 7. Referencias bibliográficas.

\section{Introducción}

La publicidad es, de toda nuestra cultura, la especie parasitaria más resistente. Sobreviviría sin duda incluso a una confrontación nuclear. Es nuestro Juicio Final. Pero también es como una función biológica; devora nuestra sustancia, pero es también como una planta parasitaria o la flora intestinal, lo que nos permite metabolizar lo que absorbemos, convertir el mundo y la violencia del mundo en una sustancia consumible.

Jean Baudrillard (1991: 23)

Con estas palabras, Jean Baudrillard captó a la perfección ya hace más de dos décadas la esencia del mundo en el que vivimos, donde absolutamente todo se ha convertido en un bien de consumo. En un contexto tal, en el que la inmensa mayoría de las sociedades ha adoptado como filosofía vital el "I shop, therefore I am" que denunciaba Barbara Kruger con su arte conceptual, la publicidad se ha expandido urbi et orbi hasta adquirir el don de la ubicuidad del que goza actualmente. Tanto es así que en enero de 2007 The New York Times proclamaba: "Anywhere the Eye Can See, It's Likely to See an Ad"1, demostrando de este modo que once palabras bastan para describir a la perfección la omnipresencia que caracteriza a esta herramienta de venta connatural al capitalismo en el siglo XXI.

A este respecto, resultan especialmente significativos los resultados arrojados por los estudios de la empresa estadounidense de investigación de mercados Yankelovich, Inc., que nos informan de que una persona que habita en una urbe recibe de media unos 3.000 impactos publicitarios al día, pudiendo alcanzar los 5.000 en ciudades como Nueva York. Y es que los anunciantes nos asedian en cada esquina que doblamos, en cada periódico que abrimos, en cada radio que encendemos, ya sea de manera abierta (overt advertising) o encubierta (covert advertising) (Duro 2001). Tanto es así que el mensaje "consume" es el que más veces recibimos al día, aun-

\footnotetext{
1 The New York Times, «Anywhere the Eye Can See, It's Likey to See an Ad» [consulta en línea: http://www.nytimes.com/2007/01/15/business/media/15everywhere.html?pagewanted=all; 06/12/2012].
} 
que, debido a la saturación informativa que sufrimos como consecuencia, en la mayor parte de las ocasiones ni siquiera llegamos a advertirlo.

Esta omnipresencia de "la grande poésie populaire", como Blanche-Noëlle Grünig (1990) la denomina, es sintomática del poder inconmensurable que atesora en la era de la globalización económica o "globalismo" (Beck 2008 [1997]), donde todas las facetas de la vida parecen encontrarse al servicio del consumo. Actualmente, tanto los pequeños negocios como las grandes compañías son conscientes de que, en un mundo donde las fronteras espaciales y temporales han desaparecido y en el que, como consecuencia, se han multiplicado los mercados (y a la vez la competencia), la publicidad se ha convertido en una herramienta sine qua non para sobrevivir. Y es que, tal y como afirma Bassat "muchas veces, la mayor diferencia que hay entre productos está en su publicidad, ¿o hay algún consumidor que pueda explicar las diferencias organolépticas que hay entre Soberano, Veterano y Centenario Terry? Sobre todo si se toman mezclados con café" (1999: 31-32).

\section{Cuando las campañas internacionales llegan a España}

Como elemento íntimamente ligado a la economía y a los medios de comunicación de masas, la publicidad ha traspasado, de la mano de los productos que anuncia, las ya moribundas fronteras de este mundo globalizado. A este respecto, en los últimos años hemos asistido a la proliferación de un tipo especial de campaña publicitaria que consiste en diseñar anuncios que puedan funcionar en todos (o casi todos) los mercados en los que una determinada empresa tiene presencia (Cf. Corbacho 2010, Montes 2006, Valdés 2004, Duro 2001). Esta clase de campañas, que conocemos como globales ${ }^{2}$, adquiere cada vez más peso en la publicidad mundial (Cf. Bassat 1999), hasta el punto de que ya se ha convertido en una herramienta fundamental de muchas multinacionales que dirigen sus productos a un grupo transnacional de consumidores con idénticos hábitos de consumo.

Las ventajas que presentan los anuncios globalizadores parecen haber decantado la balanza a su favor. En su artículo "La publicidad a nivel internacional: estrategias, condicionantes y límites", Juan Manuel Corbacho analiza algunos de estos beneficios. Según este autor, el éxito de dichas campañas internacionales se debe a que permiten a las multinacionales que recurren a ellas "[conseguir] una reducción de costes, evitar la confusión por varios mensajes, crear una imagen internacional fuerte e incrementar la eficacia comunicativa" (2010: 7). En este contexto, la traducción se ha convertido en una herramienta imprescindible que los publicistas deben manejar con pericia si desean que sus anuncios triunfen en distintos mercados a lo largo y ancho del globo, en países no sólo lingüísticamente diferentes, sino también culturalmente dispares.

A este respecto, hemos advertido que en España existe en la actualidad una tendencia creciente a emitir campañas internacionales que presentan una característica

\footnotetext{
2 Estas campañas también reciben el nombre de "internacionales", "globalizadoras" o "estandarizadoras", dependiendo del autor.
} 
especialmente interesante desde el punto de vista traductológico, que consiste en el recurso cada vez más frecuente a la no traducción de palabras y expresiones procedentes de otras lenguas, en su gran mayoría anglicismos y galicismos. En relación a esta cuestión resultan muy relevantes las palabras de Javier Vellón, quien afirma que en España "el inglés forma parte del discurso publicitario hasta el punto de definirse como un signo identificador de esta tipología textual" (2009: 157). Y así lo percibimos los receptores, quienes no nos sorprendemos ante expresiones como "unconventional chic", "fragances for women" o "le nouveau parfum fémenin", pues la presencia de estas lenguas ya se encuentra, en términos barthianos, naturalizada (1999 [1957]) (Vidal 2013).

Esta presencia de extranjerismos en el discurso publicitario ya ha sido objeto de múltiples estudios realizados en el seno de diversas disciplinas como el análisis del discurso, la pragmática o los estudios de la comunicación (Corbacho 2010, Vellón 2009, Bhatia 1992). En cuanto al campo de la traductología, los análisis se han limitado fundamentalmente a la publicidad impresa (Montes 2006, Bouazza 2005, Valdés 2004, Duro 2001), por lo que carecemos de estudios que profundicen en las estrategias traductoras que se llevan a cabo en anuncios de otra naturaleza, como los audiovisuales o los cada vez más numerosos multimodales.

En aras de contribuir a paliar dicha escasez de investigaciones en el ámbito de la publicidad no impresa analizaremos en estas páginas un fenómeno de reciente aparición en los anuncios audiovisuales de nuestro país: el recurso a una estrategia traductora que hemos denominado de "(no) traducción”, que consiste en subtitular el mensaje del spot en español mientras el audio se mantiene en inglés. Hemos adoptado esta denominación de África Vidal (2013), quien la aplica al contexto de la prensa femenina española para referirse al hecho de que en dichas publicaciones se deja sin traducir una cantidad muy elevada de términos procedentes del inglés. Desde nuestro punto de vista, esta expresión define a la perfección el fenómeno que nos ocupa, puesto que, si bien es cierto que los subtítulos traducen el mensaje del anuncio, siempre se mantienen en un segundo plano, y en muchas ocasiones directamente son obviados por el público. La razón estriba en que estas líneas de texto, además de exigir un esfuerzo añadido al espectador, tienen que competir por la atención del público con la imagen, que por lo general es mucho más poderosa. A este respecto, Antonia Montes afirma que:

El receptor dedica un promedio de dos segundos a la percepción de un anuncio cuya comprensión en su totalidad requeriría 35 a 40 segundos. Ante tal brevedad de atención, el anuncio debe transmitir un intenso estímulo y una fuerte curiosidad por el producto anunciado, con el propósito de persuadir y seducir al receptor para que el mensaje publicitario penetre en su mente y pueda surtir efecto (2006: 3).

El auténtico mensaje reside, pues, en el audio, que se mantiene en inglés, y no en los subtítulos. Y es que, como demostraremos a lo largo de este artículo, dichos anuncios no se dirigen al intelecto, sino a las emociones, por lo que la (no) traducción se emplea en este contexto como una herramienta de seducción. No obstante, antes de continuar resulta imprescindible fijar los parámetros de nuestro estudio. 


\section{Metodología}

En primer lugar, cabe delimitar y definir la muestra de anuncios que constituye el corpus de referencia que hemos seleccionado para el presente estudio. Como ya indicamos en el apartado anterior, nos interesamos en esta ocasión por cuñas televisivas que forman parte de campañas publicitarias internacionales ${ }^{3} \mathrm{y}$ en las que se lleva a cabo una estrategia de (no) traducción, de manera que el audio se mantiene en inglés mientras que el mensaje en español se relega al segundo plano de los subtítulos (o más bien tercero, si tenemos en cuenta la supremacía de la imagen).

A este respecto, debemos señalar que la emisión en España de anuncios completamente en inglés constituye un fenómeno de reciente aparición, pues hasta hace pocos años la presencia de este idioma no solía abarcar más que el eslogan o el jingle, mientras que el grueso del mensaje llegaba al público español en su lengua materna. En aras de garantizar una muestra homogénea, hemos optado por descartar este tipo de spots. Lo que aquí nos interesa son aquellas cuñas publicitarias en las que todo el diálogo o monólogo se produce en inglés (y en algún caso esporádico incorporando también francés). En total, nuestro corpus está compuesto por trece anuncios, que si bien no se trata de una cantidad muy elevada, consideramos que es suficiente para ilustrar nuestra tesis, pues no perseguimos realizar aquí un análisis cuantitativo, sino describir una práctica traductológica concreta así como las causas que motivan su empleo. Además, cabe señalar a este respecto que nuestro análisis se centra en un fenómeno de reciente aparición en nuestro país, por lo que el número de anuncios que presenta estas características es todavía reducido. No obstante, tal y como puede comprobarse en la tabla recogida en el apéndice, esta estrategia se emplea cada vez con mayor frecuencia, lo que nos proporciona un motivo añadido para reflexionar acerca de ella.

En cuanto a la metodología empleada, hemos optado por un enfoque interdisciplinar, pues consideramos que, siendo la traducción un campo epistemológico abierto al mundo, no puede analizarse en compartimentos estancos. Por ello, hemos adoptado de los estudios descriptivos de la traducción los conceptos de ideología y poder, que nos han permitido observar el lenguaje con espíritu crítico. Asimismo, hemos recurrido a las teorías sociológicas de Pierre Bourdieu que la sociología de la traducción ha comenzado a utilizar recientemente, en especial a la noción de "capital simbólico". De este modo, pretendemos demostrar que la elección de la estrategia traductora que nos ocupa no es un hecho inocente, sino que constituye una herramienta más al servicio del consumo. Su objetivo no consiste, pues, en comunicar, sino en aumentar las ventas a través de un uso persuasivo y seductor de la lengua. Porque, tal y como constata Miguel Duro en Traducir publicidad o el arte de pasar hambre: "Se puede afirmar, sin temor a cometer errores, que, en la comunicación publicitaria, el emisor no es precisamente inocente, casual, despreocupado y bisoño,

\footnotetext{
3 Aunque en nuestro análisis nos ciñamos exclusivamente al caso español, estimamos importante señalar que esta estrategia de (no) traducción también se ha llevado a cabo para la emisión de prácticamente la totalidad de los anuncios aquí estudiados en otros países como Francia e Italia.
} 
sino más bien todo lo contrario: un experto que cuida hasta el último detalle lo que quiere transmitir al destinatario y cómo quiere transmitirlo" (2001: 68). El idioma del anuncio tiene, pues, una importancia capital. Como afirma Álex Grijelmo, quien en todo momento encuentra las palabras justas: "[...] siempre habrá en quien intente seducir con las palabras un atisbo de consciencia cuando las emplee para la seducción. Las habrá descubierto intuitivamente, siendo hablado por el idioma, pero las pronunciará con plena responsabilidad. Con la intención de manipular a los incautos" (2007 [2001]: 41). Llegados a este punto, la pregunta que nos planteamos es la siguiente: ¿por qué el inglés? A lo largo de este artículo trataremos de responder a esta cuestión. Para ello analizaremos qué es lo que la actual lingua franca aporta a estos spots y procuraremos descubrir por qué este idioma contribuye de manera tan eficaz a seducir al público receptor. En definitiva, trataremos de averiguar qué es lo que se cuela, para decirlo con Foucault (1992 [1979]), a través de las palabras y los sonidos de este código internacional, que no es sino otra forma de poder que fluye entre todo lo que existe.

\section{Inglés y globalización}

Desde finales de la Segunda Guerra Mundial y debido a la consolidación de Estados Unidos como primera potencia mundial en todos los sentidos y ámbitos imaginables (económico, militar, cultural, industrial, tecnológico, cinematográfico, etc.), el inglés se ha convertido en el código de comunicación internacional por excelencia, lo que se conoce como lingua franca. Tanto es así que, actualmente, la lengua de Shakespeare es también la de la economía, la política, el turismo, los negocios, el discurso académico, la ciencia, el cine, etc. Asimismo, goza de carácter de idioma oficial en todas las organizaciones con peso político y económico del mundo (OTAN, ONU, etc.) y en muchas otras, como la Unión Europea, se utiliza, además, como lengua de trabajo.

El debate sobre la supremacía del inglés es a día de hoy un tema candente. Son muchos los investigadores y académicos que se han pronunciado y se pronuncian al respecto. A grandes rasgos, podemos afirmar que existen dos posturas bien diferenciadas. Por un lado, hay quien distingue entre el uso del inglés como lingua franca, que ambas partes aceptan en mayor o menor medida como medio de comunicación, y "lengua dominante", que trae consigo una determinada cosmovisión, unos valores, una cultura (Vidal 2007: 57). En esta línea se encuentran investigadoras de prestigio internacional como Juliane House, para quien la actual lingua franca "is a language for communication [...] not a language for identification" (2010: 13), o Mary Snell-Hornby, quien afirma que nos encontramos ante el "International English" que ha perdido su identidad cultural originaria (2000: 17) y se ha convertido en "the 'McLanguage' of our globalised 'McWorld' or the 'Eurospeak' of our multilingual continent" (citado por Bielsa y Bassnett 2009: 30).

Por otro lado, existe hoy en día una fuerte línea de pensamiento con muchos adeptos y defensores que ven en el uso del inglés como lengua de comunicación internacional una forma más de dominio por parte de la gran potencia económica y política 
mundial. Los partidarios de esta corriente son muy conscientes de que lenguaje y poder son una unidad indivisible y de que, en consecuencia, quien controle el código dominante controlará el discurso y por ende el poder (Cf. Vidal 2007, Talens 2006, Bourdieu y Wacquant 2001). De entre todas las opiniones, nos resulta especialmente reveladora para el tema que nos ocupa aquella defendida por autores como Alastair Pennycook y Brian Lennon, quienes consideran que la fuerza de la lengua inglesa reside en el hecho de que posee, en términos bourdesianos, un gran capital simbólico que la convierte en una riqueza para los hablantes nativos y en un objeto de deseo para los no nativos, dado que constituye un certificado que garantiza el acceso al poder:

It is the history of the accumulated capital associated with English that gives it power. It is the potential it offers-to open social networks, to provide access to economic privilege, to help accrue the cultural capital of education systems, the potential perhaps above all to show one's possession of the symbolic capital of English-that gives it its power. Language has power, argues Bourdieu, because of the power of its users (Pennycook 1997: 3-4).

The dominance of U.S. English in the world today can be understood as a function of the power wielded by U.S. English as cultural capital, not by the natural genius, or any other genetic quality, of English (or one of its variants) as a language among others. English is the language happening to possess powers of legitimation and consecration -a form of inherited wealth for native speakers, an object of desire for nonnative speakers, where English accreditation confers "institutionalized" cultural capital: a certificate guaranteeing access to power (Lennon 2010: 29).

En esta investigación nos posicionamos en la misma línea que Alastair

Pennycook y Brian Lennon. A continuación trataremos de demostrar que el hecho de que se haya decidido mantener el audio en inglés en la muestra de anuncios analizada se debe al capital simbólico que posee esta lengua.

\section{El inglés como herramienta de seducción en los spots televisivos emitidos en España}

Como ya indicamos en el apartado anterior, el inglés es en la actualidad la lengua de comunicación internacional por excelencia. No obstante, las características propias del público español nos obligan a descartar la intención comunicativa en el uso de este idioma en la publicidad que se emite en nuestro país. Y es que no es lo mismo televisar un anuncio completamente en inglés en Suecia o Dinamarca, donde una gran parte de la población presenta un elevado conocimiento de esta lengua, a hacerlo en España, un país que, de acuerdo con el informe publicado en 2012 por la agencia $\mathrm{EF}^{4}$, presenta uno de los niveles de conocimiento de inglés más bajos de

\footnotetext{
${ }^{4}$ EF (Education First). The EF EPI 2012 Report.

[consulta en línea: http://www.ef.com.es/epi/downloads/; 05/12/2012].
} 
toda la Unión Europea. Ni siquiera las generaciones más jóvenes con estudios universitarios alcanzan el nivel necesario para comprender estos spots sin ningún tipo de apoyo como transcripciones o subtítulos, por no hablar de las más mayores, que en muchos casos no han tenido nunca contacto con esta lengua.

En consecuencia y como apuntábamos antes, resulta evidente que en la muestra analizada la intención comunicativa queda desplazada en beneficio de la persuasiva. En estas cuñas, el inglés se convierte en una herramienta de seducción que los publicistas utilizan para llegar a la parte emocional de sus receptores, pues saben que, tal y como señala Antonio López: "en publicidad lo psicológico es más eficaz que lo lógico" (2004: 104). Y es que los autores de estas herramientas de venta son perfectamente conscientes de que en el contexto de las actuales sociedades capitalistas, donde los mercados se encuentran saturados por productos de características cuasi idénticas, la clave del éxito publicitario reside en alcanzar la parte emocional del público. Antonia Montes también destaca esta cuestión en su artículo "Globalización y publicidad: el lenguaje universal de los perfumes", donde afirma que:

Debido a la saturación del mercado con productos de similares características, la publicidad tiene que transmitir valores que vayan más allá de las puras necesidades. Se trata de dotar al producto de atributos anhelados, entre otros mediante la apelación a valores hedónicos, y convencer al consumidor que sólo con la adquisición de un determinado producto conseguirá la satisfacción de sus deseos más profundos (2006:4).

He aquí la clave que explica la presencia de la lengua inglesa en los anuncios analizados: su capacidad para seducir al público mediante la activación de referencias positivas que se encuentran acumuladas en el inconsciente colectivo. Y es que, tal y como Javier Vellón señala:

El uso exclusivo del inglés, en un anuncio destinado al mercado español, no es un simple fenómeno dirigido a crear efectos puntuales, ocurrencias con fines de idoneidad perceptiva, sino un mecanismo capaz de articular las diferentes dimensiones semióticas y performativas del discurso publicitario a través de los textos públicos, es decir, la económica, empresarial, cultura y argumentativa (2009: 159).

En consecuencia, podemos afirmar que en estos spots el inglés no se dirige a nuestro intelecto, sino a nuestras emociones. Y es que las palabras no solo denotan, sino que, sobre todo, connotan. Es ahí, en el poder de evocación de otros mundos, otras realidades, otros conceptos, otras emociones, donde reside el verdadero poder de seducción de lo que antaño considerábamos simples contenedores de significado. Álex Grijelmo analiza en profundidad esta cuestión en su obra titulada con tanto atino La seducción de las palabras, donde afirma que:

La seducción parte de las connotaciones, de los mensajes entre líneas más que de los enunciados que se aprecian a simple vista. La seducción de las palabras no busca el sonido del significante, que llega directo a la mente racional, sino el significante del sonido, que se percibe por los sentidos y termina, por tanto, en los sentimientos (2007 [2001]: 39). 
Vemos, pues, que la decisión de no traducir el audio de estos anuncios no es casual, neutra, ni inocente. En ellos, el inglés se emplea como un idioma icono (Montes 2006: 2) o lengua-símbolo (Grijelmo 2007 [2001]: 172) que, a través de sus connotaciones, va conformando el sentido del discurso. Pero, ¿cuáles son estos "significados de segundo orden", para decirlo con Roland Barthes (1999 [1957]), que transmite la lengua anglosajona? Para responder a este interrogante, debemos dirigir nuestro análisis necesariamente hacia la sociedad, tal y como postula la sociología de la traducción, dado que consideramos que un fenómeno lingüístico como la traducción nunca puede estudiarse al margen de la sociedad que la produce y la consume.

Desde esta óptica, lo primero que se percibe es que el inglés ocupa actualmente un puesto central y privilegiado en nuestro mundo globalizado. Como lengua de la primera potencia económica mundial, goza de un prestigio sin parangón que parece trasmitir a todo aquello que toca. $Y$ es que, tal y como señalamos en el apartado anterior, como lengua del poder, y en consecuencia, con poder, ha pasado a evocar todos los aspectos positivos imaginados e imaginables, condición que se encuentra grabada en el inconsciente colectivo. A este respecto, resultan especialmente significativas las palabras de Assam Bouazza, quien afirma que:

El uso de la lengua inglesa $[\ldots]$ crea una sensación positiva y de cercanía del receptor con el producto a partir de la red de relaciones evocativas por las asociaciones mentales que activa el uso del lenguaje con las referencias acumuladas en el inconsciente colectivo. La referencia en este caso es principalmente el universo estadounidense $[\ldots]$ que ha afianzado valores inconfundiblemente relativos a dicha cultura como: la libertad, la aventura, la acción, el dinamismo mental y práctico, etc. (2005: 681).

En el caso de las cuñas que aquí nos ocupan, el inglés contribuye a reforzar aquellos valores con los que el anuncio pretende seducir a su público. La razón de que la lengua elegida sea esta y no otra reside, como venimos insistiendo desde las primeras páginas, en su capital simbólico. Según Bourdieu, este se define como "cualquier propiedad (cualquier tipo de capital, físico, económico, cultural, social) cuando es percibida por agentes sociales cuyas categorías de percepción son de tal naturaleza que les permiten conocerla (distinguirla) y reconocerla, conferirle algún valor" (1997: 108). Para ilustrar su explicación, el sociólogo francés toma como ejemplo el caso del honor en las sociedades mediterráneas, dado que este solo existe en la medida en que sus habitantes comparten unos valores que les hacen percibir ciertas actitudes y comportamientos como honorables y otros como deshonrosos. En el caso del inglés, tal y como hemos señalado en párrafos anteriores, su capital simbólico reside en que las distintas sociedades lo perciben como la lengua del progreso (Crystal 1997), como un idioma que franquea al que lo domina el acceso al poder. Si no existieran en nuestro inconsciente colectivo multitud de referencias positivas asociadas a este código, la estrategia de (no) traducción que nos ocupa no conseguiría su objetivo. A continuación analizaremos brevemente cuáles son los valores que motivan la presencia de este idioma en la muestra seleccionada. Para ello, hemos optado por 
centrarnos en aquellos que aparecen con mayor frecuencia, a saber, la seducción, la libertad y la fama.

Comenzaremos nuestro análisis por el concepto de seducción por constituir este casi una constante en la muestra analizada. Como lengua de la belleza, de las pasarelas y de la factoría hollywoodiense, el inglés se encuentra íntimamente relacionado en nuestro inconsciente colectivo con la atracción física. Se trata de un idioma que, como podemos observar en los siguientes extractos, acentúa la incitación y sugerencia de las palabras que pronuncian las protagonistas de estos spots:

My favorite part of my body? ... I like my lips. For kissing. I do all my own scenes. Even lovemaking. Oh, I'm not looking for a million things, just that one, perfect thing, love. That's the one (Anun. 7; véase el apéndice).

I don't deny it... I love Schweppes. I like to have Schweppes with strangers. And you? Would you have some Schweppes... just me and you? (Anun. 9; véase el apéndice).

Comprobamos pues, que estos anuncios tratan de seducir prometiendo precisamente eso: seducción. En este contexto, el inglés contribuye con sus connotaciones positivas a la creación de universos simbólicos capaces de atraer al público. A este respecto, resulta especialmente significativo el siguiente spot, pues en él, además de la lengua anglosajona se emplea asimismo el francés, que aporta otras connotaciones, como la pasión, la dulzura y el coqueteo:

Chloé, tu es là? Je sais que tu es là. Pick up the phone, baby, please, pick up the phone. You were so pretty yesterday. Je veux te revoir... (Anun. 13; véase el apéndice).

El resultado es una seducción bilingüe capaz de activar en nuestras mentes las sensaciones positivas que nos aporta el francés, como las ligadas al amor, a la pasión y a la ternura, y las asociadas al inglés, como la juventud, la modernidad y el cosmopolitismo. A este respecto, cabe señalar que tradicionalmente la seducción hablaba en francés o, en última instancia, en italiano. No obstante, tal y como evidencian los anuncios aquí analizados, en los últimos años esta tendencia se ha invertido a favor de la lengua anglosajona. No ocurre lo mismo, sin embargo, con el segundo concepto que nos ocupa, la libertad, que ha sido y continúa siendo un feudo exclusivo de la actual lingua franca, tal y como podemos comprobar en los siguientes extractos:

Empty your mind. Be formless, shapeless. Like water. You put water into a bottle and it becomes the bottle. You put it in a teapot, it becomes the teapot. Water can flow, or it can crash. Be water, my friend (Anun. 2; véase el apéndice).

The best thing about getting lost is what you find along the way. Here or there, I'm just gone. Anywhere I end up, I'm just free (Anun. 5; véase el apéndice). 
$>$ Sin lugar a dudas, la libertad constituye el pilar principal sobre el que se erige todo el sistema de valores estadounidense. Como podemos observar en estos ejemplos, el inglés contribuye con sus connotaciones a reforzar esa sensación de libertad, de posibilidades ilimitadas, de control sobre nuestras propias vidas que se encuentra en nuestro inconsciente colectivo íntimamente ligada a este país. Y es que, a lo largo de toda su historia, Estados Unidos siempre se ha erigido como patria de todas las libertades. En los siguientes extractos, podemos observar claras referencias al self-made man, ese hombre libre que es dueño de las riendas de su propia vida:

Who's gonna tell me when to stop, which way to go, who's right, or wrong? Who's gonna judge me? ME (Anun. 4; véase el apéndice).

I'm not going to be the person I'm expected to be anymore. Be unexpected (Anun. 6; véase el apéndice).

Por último, nos referiremos brevemente al concepto de fama, otro de los valores principales que transmiten los anuncios analizados y que el inglés contribuye a reforzar. No obstante, es este un aspecto que difícilmente podemos analizar a través de los diálogos, puesto que no necesariamente se traduce en lenguaje. Se trata más bien de una noción que permea todos los anuncios aquí recogidos y que está íntimamente relacionada con el personaje que los protagoniza: actrices, actores y modelos de fama mundial (véase el apéndice) que, al igual que el inglés, aportan connotaciones positivas de éxito, reconocimiento, autorrealización, belleza, seducción, felicidad en definitiva. Y es que en publicidad todos los elementos, desde los colores hasta los idiomas, ascienden a categoría de símbolos y colaboran para dotar a las marcas de una significación imaginaria (Caro 2010: 122). Por esta razón, dado que en este contexto absolutamente todo significa, no podemos analizar la estrategia de (no) traducción que nos ocupa de forma aislada, sin tomar en consideración el resto de componentes que conforman cada una de las cuñas publicitarias.

\section{Conclusiones}

Tal y como hemos tratado de demostrar en estas páginas, la publicación de spots televisivos en los que se opta por aplicar una estrategia de (no) traducción es cada vez más frecuente en el ámbito publicitario español. La decisión de mantener el audio en inglés en estos anuncios no es inocente, sino que la lengua anglosajona se ha convertido en una herramienta más de la que se sirven los publicistas para conseguir esa seducción necesaria para lograr las ventas de aquello que anuncian. $\mathrm{Y}$ es que saben muy bien que:

Muchos eligen una marca de tabaco o una de zumo, pero luego serían incapaces de distinguirlas al gusto. La conclusión de los técnicos es formal: no fumamos 
cigarrillos, sino imágenes de cigarrillos; no tomamos bebidas, sino sensaciones mentales de las bebidas. Es igualmente evidente que las mujeres no compran cremas suavizantes, astringentes o rejuvenecedoras, sino imágenes de la juventud, del éxito, del amor [...] El comercio vende símbolos. Y esos símbolos funcionan en los niveles subconscientes e inconscientes, en los ámbitos irracionales (Grijelmo 2007 [2001]: 117. Nuestra cursiva).

La presencia del inglés se debe, en consecuencia, a su perfume, como tan acertadamente indica Álex Grijelmo (2007 [2001]). Pocas expresiones conocemos que expresen de un modo tan preciso y sutil esa capacidad de connotación que poseen los vocablos de una lengua y, en definitiva, todos los signos. Y es que el perfume nos provoca sensaciones, nos transporta a otros mundos, nos atrae, nos seduce. Como hemos podido comprobar en los anuncios estudiados, el inglés sugiere belleza, juventud (una cualidad cada vez más apreciada en nuestras sociedades occidentales), prestigio, reconocimiento, felicidad. Es, en definitiva, sinónimo de éxito. Como traductores debemos reflexionar sobre este poder ilimitado que poseen no solo las palabras, sino también los idiomas cuando ellos mismos actúan como signos. Y, sobre todo, debemos ser siempre conscientes de que, tal y como afirmaba Pierre Bourdieu: "no existen palabras neutras [...] no existen palabras inocentes" (2008 [1982]: 15-16). Como profesionales del lenguaje que somos, debemos sumergirnos en la parte más profunda de los vocablos, en su alma. No podemos olvidar que, al igual que los perfumistas, los traductores trabajamos con esencias, siempre invisibles pero sin duda alguna poderosas.

\section{Referencias bibliográficas}

Barthes, R., Mitologías. Madrid: Siglo XXI 1999 [1957]. Trad. Héctor Schmucler.

BASSAT, L., El libro rojo de las marcas (Cómo construir marcas de éxito). Madrid: EspasaCalpe 1999.

BAUdRILlARD, J., La guerra del Golfo no ha tenido lugar. Barcelona: Editorial Anagrama 1991. Trad. Thomas Kauf.

BECK, U., ¿Qué es la globalización? Falacias del globalismo, respuestas a la globalización. Barcelona: Paidós 2008 [1997]. Trad. Bernardo Moreno y Mª Rosa Borràs.

Bhatia, T. J., «Discourse Functions and Pragmatics of Mixing: Advertising Across Cultures», World Englishes 11 (1992), 195-215.

Bielsa, E. / Bassnett, S., Translation in Global News. London / New York: Routledge 2009.

BouAzZA, A., «¿Traducción en la publicidad? Notas traductológicas sobre el tratamiento fraseológico en el discurso publicitario», en: II AIETI. Actas del II Congreso Internacional de la Asociación Ibérica de Estudios en Traducción e Interpretación (Madrid 9-11 de febrero de 2005).

Bourdieu, P., ¿Qué significa hablar? Economía de los intercambios lingüísticos. Madrid: Ediciones Akal 2008 [1982]. Trad. Esperanza Martínez Pérez.

Bourdieu, P. / L. WACQUANT, «Neoliberal Newspeak: Notes on the New Planetary Vulgate», Radical Philosophy 105 (2001), 2-5.

Bourdieu, P., Razones prácticas. Sobre la teoría de la acción. Barcelona: Anagrama 1997. Trad. Thomas Kauf. 
CARo, A., «Publicidad y globalización», Historia y Comunicación Social 15 (2010), $117-$ 130.

Corbacho VAlencia, J. M., «La publicidad a nivel internacional: estrategias, condicionantes y límites», en: Actas del II Congreso Internacional AE-IC (Málaga 3-5 de febrero de 2010).

CRYSTAL, D., English as a Global Language. Cambridge: Cambridge University Press 1997.

Duro Moreno, M., Traducir publicidad o el arte de pasar hambre. Granada: Editorial Comares 2001.

Foucault, M., El orden del discurso. Buenos Aires: Tusquets 1992 [1979]. Trad. Alberto González Troyano.

GriJelmo, A., La seducción de las palabras. Madrid: Santillana 2007 [2001].

GRÜNIG, B., Les mots de la publicité: l'architecture du slogan. Paris: Presses du CNRS 1990.

House, J., «English as a Global Lingua Franca: a Threat to Multilingualism», en: Shiyab,

S.M. [et al.] (eds.), Globalization and Aspects of Translation. Newcastle upon Tyne: Cambridge Scholars Publishing, 2010, 11-35.

Lennon, B., In Babel's Shadow. Minneapolis: University of Minnesota Press 2010.

LÓPEz EIRE, A., «Retórica y publicidad en la era de la globalización», Logo: Revista de Retórica y Teoría de la Comunicación 6 (2004), 95-121.

MonTES FERnÁndez, A., "Globalización y publicidad: el lenguaje universal de los perfumes», Hispanogalia 2 (2006), 217-226.

PenNyCOOK, A., «English and Capital: Some Thoughts» (2007) (consulta en línea: http://jaltpublications.org/old_tlt/files/97/oct/pennycook.html; 06/12/2012).

SNELL-Hornby, M., "Communicating in the Global Village: On Language, Translation and Cultural Identity» en: Schäffner, C. (ed.), Translation in the Global Village. Clevedon: Multilingual Matters, 2000, 11-28.

TAlens, J., «La indagación del texto», Debats 92 (2006).

VAldés Rodríguez, C., La Traducción publicitaria: comunicación y cultura. Bellaterra: Universitat Autónoma de Barcelona, Servei de Publicacions 2004.

Vellón, J., «El uso del inglés como estrategia discursiva en el texto publicitario», Cultura, Lenguaje y Representación 7 (2009), 157-182.

Vidal Claramonte, M.C.A., Traducir entre culturas. Frankfurt: Peter Lang 2007.

Vidal Claramonte, M.C.A., «El lenguaje de las revistas femeninas españolas: la (no) traducción como ideología», Meta 58 (2013) (en prensa). 


\section{Apéndice: muestra de anuncios analizada}

\begin{tabular}{|c|c|c|c|c|c|}
\hline Ref. & Título & Año & Compañía & Protagonista(s) & Leng. \\
\hline Anuncio 1 & What Else? & 2006 & Nespresso & George Clooney & Ing. \\
\hline Anun. 2 & $\begin{array}{l}\text { Be Water, my } \\
\text { Friend }\end{array}$ & 2006 & $\mathrm{BMW}^{5}$ & Bruce Lee & Ing. \\
\hline Anun. 3 & Heaven Can't Wait & 2009 & Nespresso & $\begin{array}{l}\text { George Clooney y } \\
\text { John Malkovich }\end{array}$ & Ing. \\
\hline Anun. 4 & Only the Brave & 2010 & Diesel & Sam Way & Ing. \\
\hline Anun. 5 & Free Men & 2010 & Calvin Klein & Jamie Dornan & Ing. \\
\hline Anun. 6 & $\begin{array}{l}\text { Bleu de Chanel: } \\
\text { The Film }\end{array}$ & 2010 & Chanel & Gaspard Ulliel & Ing \\
\hline Anun. 7 & The One & 2011 & $\begin{array}{l}\text { Dolce \& } \\
\text { Gabbana }\end{array}$ & Scarlett Johansson & Ing. \\
\hline Anun. 8 & The Taxi & 2010 & Nespresso & $\begin{array}{l}\text { George Clooney y } \\
\text { John Malkovich }\end{array}$ & Ing. \\
\hline Anun. 9 & $\begin{array}{l}\text { What Did You } \\
\text { Expect? }\end{array}$ & 2011 & Schweppes & Uma Thurman & Ing. \\
\hline Anun. 10 & The Swap & 2011 & Nespresso & $\begin{array}{l}\text { George Clooney y } \\
\text { Nazanin Boniadi }\end{array}$ & Ing. \\
\hline Anun. 11 & There You Are & 2012 & Chanel & Brad Pitt & Ing. \\
\hline Anun. 12 & Like a Star & 2012 & Nespresso & George Clooney & Ing. \\
\hline Anun. 13 & $\begin{array}{l}\text { Chloé: Eau de } \\
\text { Parfum }\end{array}$ & 2012 & Chloé & Suvi Koponen & Ing./ fr. \\
\hline
\end{tabular}

${ }^{5}$ Este anuncio, al contrario que los demás, no forma parte de una campaña internacional, sino que fue creado directamente para el público español. No obstante, lo incluimos en nuestra muestra porque consideramos que el uso del inglés responde en su caso a las mismas razones que en el resto. Como dato significativo añadiremos que con este spot la empresa automovilística aumentó las ventas del modelo anunciado en un $73 \%$ en tan solo un año, lo que le valió a la compañía publicitaria el Premio a la Eficacia en 2007. 